\title{
Translationally controlled tumour protein (TCTP) is a novel glucose-regulated protein that is important for survival of pancreatic beta cells
}

\author{
F. Diraison • K. Hayward • K. L. Sanders • F. Brozzi • \\ S. Lajus • J. Hancock • J. E. Francis • E. Ainscow • \\ U. A. Bommer • E. Molnar • N. D. Avent • A. Varadi
}

Received: 21 July 2010 /Accepted: 27 September 2010 /Published online: 10 November 2010

(C) Springer-Verlag 2010

\begin{abstract}
Aims/hypothesis This study used proteomics and biochemical approaches to identify novel glucose-regulated proteins and to unveil their role in pancreatic beta cell function. Translationally controlled tumour protein (TCTP) was identified to be one such protein, and further investigations into its function and regulation were carried out.

Methods Global protein profiling of beta cell homogenates following glucose stimulation was performed using twodimensional gel electrophoresis. Proteins were identified by mass spectroscopy analysis. Immunoblotting was used to investigate alterations in TCTP protein levels in response to glucose stimulation or cell stress induced by palmitate. To investigate the biological function of TCTP, immunolocalisation, gene knockdown and overexpression of Tctp (also
\end{abstract}

F. Diraison, K. Hayward and K. L. Sanders contributed equally to this study.

Electronic supplementary material The online version of this article (doi:10.1007/s00125-010-1958-7) contains supplementary material, which is available to authorised users.

F. Diraison $\cdot$ K. Hayward $\cdot$ K. L. Sanders $\cdot$ F. Brozzi $\cdot$ S. Lajus $\cdot$

J. Hancock $\cdot$ N. D. Avent $\cdot$ A. Varadi $(\bowtie)$

Centre for Research in Biomedicine,

Faculty of Health and Life Sciences,

University of the West of England,

Bristol BS16 1QY, UK

e-mail: Aniko.Varadi@uwe.ac.uk

J. E. Francis $\cdot$ E. Ainscow

Advanced Science and Technology Laboratory, AstraZeneca,

Loughborough, UK

U. A. Bommer

Graduate School of Medicine,

University of Wollongong,

Wollongong, NSW, Australia known as $T p t 1$ ) were performed. Apoptosis was measured in Tctp knockdown or Tctp-overexpressing cells. Glucosestimulated insulin secretion was carried out in Tctp knockdown cells.

Results TCTP was identified as a novel glucose-regulated protein, the level of which is increased at stimulatory glucose concentration. Glucose also induced TCTP dephosphorylation and its partial translocation to the mitochondria and the nucleus. TCTP protein levels were downregulated in response to cell stress induced by palmitate or thapsigargin treatments. Gene knockdown by small interfering RNA led to increased apoptosis, whereas overproduction of TCTP prevented palmitate-induced cell death.

Conclusions/interpretation Regulation of TCTP protein levels by glucose is likely to be an important cyto-protective
E. Molnar

MRC Centre for Synaptic Plasticity,

School of Physiology and Pharmacology, University of Bristol,

Bristol, UK

Present Address:

K. L. Sanders

Sir James Black Centre, College of Life Sciences,

University of Dundee,

Dundee, UK

Present Address:

N. D. Avent

School of Biomedical and Biological Science,

University of Plymouth,

Plymouth, UK 
mechanism for pancreatic beta cells against damage caused by hyperglycaemia. In contrast, high concentration of palmitate causes cell stress, reduction in TCTP levels and consequently reduced cell viability. Our results imply that TCTP levels influence the sensitivity of beta cells to apoptosis.

Keywords Apoptosis $\cdot$ Fatty acid palmitate $\cdot$ Insulin secretion $\cdot$ Proteomics analysis $\cdot$ TCTP Translationally controlled tumour protein

$\begin{array}{ll}\text { Abbreviations } \\ \text { BAX } & \text { BCL2-associated X protein } \\ \text { BCL2 } & \text { B cell lymphoma 2 } \\ \text { 2DGE } & \text { Two-dimensional gel electrophoresis } \\ \text { ER } & \text { Endoplasmic reticulum } \\ \text { ERK1/2 } & \text { Extracellular signal regulated kinase } \\ \text { GAPDH } & \text { Glyceraldehyde 3-phosphate dehydrogenase } \\ \text { IPG } & \text { Immobilised pH gradient } \\ \text { MCL-1 } & \text { Myeloid cell leukaemia sequence 1 } \\ \text { PERK } & \text { PKR-like ER kinase } \\ \text { PKR } & \text { Double-stranded RNA-dependent protein kinase } \\ \text { siRNA } & \text { Small interfering RNA } \\ \text { TCTP } & \text { Translationally controlled tumour protein } \\ \text { UPR } & \text { Unfolded protein response }\end{array}$

\section{Introduction}

Using a proteomics-based approach, we identified and characterised glucose-regulated proteins in pancreatic beta cells. Global analysis of protein levels using proteomics can unveil biologically important changes in protein production, which may not be identified by cDNA microarray analysis. The latter method is limited by the fact that mRNA levels and not their protein products are investigated. Gene expression studies based on cDNA microarrays do not always correlate with changes found at the protein level [1-3]. Furthermore, many proteins are also regulated at post-transcriptional levels, effecting changes that transcriptome analysis would fail to identify. Our proteomics-based analysis identified translationally controlled tumour protein (TCTP) as a glucose-regulated protein in pancreatic beta cells.

TCTP is a highly conserved protein of $23 \mathrm{kDa}[4,5]$, which shows no sequence similarity with any other known proteins. TCTP has been identified in a wide range of eukaryotic organisms and has been associated with diverse cellular processes, as reviewed by others [6]. However, the physiological function of TCTP in humans is still not fully elucidated. TCTP has been suggested to function as an antiapoptotic protein, since overproduction of the protein inhibits, whereas knockdown of its gene promotes apoptosis [7-12]. Gene knockout studies revealed that TCTP- deficient mice $[10,13]$ and TCTP-deficient mutants of Drosophila [14] die early during embryogenesis, presumably due to unregulated apoptosis at a critical stage. It has been shown that TCTP binds to the anti-apoptotic members of the B cell lymphoma 2 (BCL2) family of proteins, myeloid cell leukaemia sequence 1 (MCL-1) $[7,8]$ and B cell lymphoma extra large (BCL-XL) [9]. It has recently been proposed that TCTP antagonises apoptosis by enhancing the anti-apoptotic actions of MCL-1 and BCL-XL, and by anchoring into the mitochondrial membrane in a way that inhibits dimerisation of the proapoptotic protein BCL2associated $\mathrm{X}$ protein (BAX) [10]. Thus, the abovementioned studies clearly indicate that TCTP plays a critical role in the control of cell survival in vivo.

Besides its anti-apoptotic function, TCTP is required for cell growth and proliferation. For example, Drosophila TCTP was shown to control cell growth and proliferation by regulating GTPase activity of a Ras homologue, Rheb [14], although this point remains controversial, as previously discussed [11]. In addition, TCTP regulates cell growth through its guanine nucleotide dissociation inhibitor activity for the elongation factors eukaryotic elongation factor $1 \mathrm{~A}(\mathrm{eEF}-1 \mathrm{~A})$ and elongation factor $1 \mathrm{~B} \beta(\mathrm{EF} 1 \mathrm{~B} \beta$ [15]. TCTP is also a tubulin- [16] and calcium-binding [17] protein, serves as a substrate of polo-like kinase [18] and has properties of a histamine-releasing factor [19] or growth factor [20]. These diverse functions of TCTP are likely to result from its specific association with various protein partners.

TCTP levels may vary considerably between various tissues and its synthesis is regulated at the transcriptional and posttranscriptional levels [21, 22], indicating involvement of tissue-specific factors. Analysis of the mouse Tctp (also known as $T p t 1$ ) gene promoter revealed that its expression is also regulated by cAMP [23]. TCTP levels are, therefore, highly regulated in response to a wide range of extracellular signals and cellular conditions. Various stress conditions, such as starvation, heat shock, heavy metals, calcium stress or proapoptotic/cytotoxic signals can up- or downregulate TCTP levels, as previously reviewed [6]. Furthermore, TCTP levels are regulated by the double-stranded RNA-dependent protein kinase (PKR) [24]. In this context, we recently revealed that activation of PKR by pro-apoptotic stimuli results in downregulation of TCTP protein levels [11].

TCTP was first identified from tumour cells, but it has since been recognised that TCTP is not a tumour-specific protein, although its levels tend to be higher in tumours than in the corresponding normal tissue [25]. There also seems to be a link between cancer and TCTP, since inhibition of TCTP results in suppression of the malignant phenotype [25]. Intriguingly, reduced levels of TCTP have been detected in post-mortem brains from patients with Down's syndrome and Alzheimer's disease [26]. It is 
plausible that diminished anti-apoptotic protection by TCTP is involved in these disorders.

Despite the many important functions attributed to TCTP, its role in pancreatic beta cells is not known to date. The current study identified TCTP as a novel glucoseregulated protein and investigated its role in glucoseregulated insulin secretion and cell survival.

\section{Methods}

Materials All molecular biologicals were from Sigma (Poole, UK). Two-dimensional gel electrophoresis (2DGE) reagents and all secondary antibodies were from GE Healthcare (Chalfont St Giles, UK) and Invitrogen (Paisley, UK). Anti-mouse TCTP monoclonal antibody was from Stratech Scientific (Newmarket, UK). Monoclonal antiphosphotyrosine and anti-phosphoserine antibodies were from Abcam (Cambridge, UK). TCTP-specific small interfering RNA (siRNA; sc-43450) and control scrambled RNAs were from Santa Cruz (Heidelberg, Germany). Rabbit polyclonal anti-extracellular signal regulated kinase (ERK)1/2 antibody was purchased from Cell Signaling (Hitchin, UK).

Cell culture MIN6 and HIT-T15 beta cells were cultured as previously described [27]. For glucose stimulation experiments, MIN6 cells were cultured for $12 \mathrm{~h}$ in DMEM containing $3 \mathrm{mmol} / \mathrm{l}$ glucose, which was then replaced by DMEM containing 3 or $25 \mathrm{mmol} / \mathrm{l}$ glucose for $24 \mathrm{~h}$.

Isoelectric focusing and 2DGE Cell homogenate was prepared by lysing the cells in RIPA buffer $(138 \mathrm{mmol} / \mathrm{l} \mathrm{NaCl}$, $2.6 \mathrm{mmol} / 1 \mathrm{KCl}, 1.5 \mathrm{mmol} / 1 \mathrm{KH}_{2} \mathrm{PO}_{4}, 6.3 \mathrm{mmol} / 1 \mathrm{Na}_{2} \mathrm{HPO}_{4}$, $\mathrm{pH} 7$ ) containing $1 \%$ (vol./vol.) Igepal CA-630, $0.5 \%$ (wt/ vol.) sodium deoxycholate, $0.1 \%$ (wt $/ \mathrm{vol}$.) SDS. Immobilised $\mathrm{pH}$ gradient (IPG) strips $(24 \mathrm{~cm})$ were rehydrated overnight and sample cup-loaded. Isoelectric focusing was performed for $1 \mathrm{~h}$ at $500 \mathrm{~V}$ with voltage increasing step-wise from 500 to $1,000 \mathrm{~V}$, and finally to $8,000 \mathrm{~V}$ for $8 \mathrm{~h}$. Strips were equilibrated for $15 \mathrm{~min}$ in LDS sample buffer (NuPAGE, Invitrogen, Paisley, UK) in the presence of $10 \%$ (vol./vol.) NuPAGE sample reducing agent. The samples were equilibrated for $15 \mathrm{~min}$ in LDS sample buffer (NuPAGE) containing $125 \mathrm{mmol} / \mathrm{l}$ iodoacetamide. Strips were transferred on to gels (Novex 4-12\% Bis-Tris ZOOM gels; NuPAGE). The strips were overlaid with $0.5 \%$ (wt/vol.) agarose in running buffer (NuPAGE MOPS SDS) and gels run in a mini-cell device (XCell Surelock; Invitrogen).

Immunoblotting, immunocytochemistry and subcellular fractionation These were performed as described earlier
[27]. To quantify nuclear localisation of TCTP in response to glucose, imaging was performed using the same confocal settings for all conditions and the intensity of nuclear staining was quantified by a software tool (Volocity; Perkin Elmer, Waltham, MA, USA). Three loading controls were used in this study. For the 2DGE and the corresponding 1DGE, the TCTP density was normalised to that of the total protein because ERK1/2 and glyceraldehyde 3-phosphate dehydrogenase (GAPDH) showed several spots on the 2DGE. GAPDH levels increased in response to glucose and thus could not be used as loading control in experiments where the glucose level changed. Thus, ERK1/2 was used as a loading control for islet proteins [28] and also for conditions where the glucose concentration was altered.

Detection of the phosphorylation state of TCTP MIN6 beta cells were treated and proteins separated as described previously [27]. The gels were co-stained with gel stains (Pro-Q Diamond Phosphoprotein and SYPRO Ruby; Invitrogen, Paisley, UK) according to the manufacturer's instructions. The gels were imaged using a scanner (Typhoon 9210; GE Healthcare, Chalfont St Giles, UK) with excitation of 532 or $450 \mathrm{~nm}$, and emission maximum of 580 or $610 \mathrm{~nm}$ for Pro-Q Diamond and SYPRO Ruby, respectively. Immunoblots were probed with phosphotyrosine- and phosphoserine-specific antibodies.

siRNA knockdown of Tctp expression and measurement of insulin secretion This was carried out as described previously [27]. For insulin secretion, cells at $96 \mathrm{~h}$ post-transfection were incubated for $1 \mathrm{~h}$ in $\mathrm{KRB}$ at $3 \mathrm{mmol} / 1$ glucose, followed by $30 \mathrm{~min}$ incubation in $\mathrm{KRB}$ at low $(3 \mathrm{mmol} / \mathrm{l})$ or high (30 mmol/l) glucose concentrations. Insulin was measured using a kit (Ultrasensitive Mouse Insulin ELISA; Mercodia, Uppsala, Sweden).

Measurement of apoptosis following Tctp siRNA transfection Cells treated with siRNA were collected from the media and plate, and washed three times with PBS. The cell pellet was resuspended in $500 \mu \mathrm{l}$ minimal medium (DMEM without FCS) and $25 \mu \mathrm{g} / \mathrm{ml}$ propidium iodide was added immediately before analysis. Fluorescence intensity of the propidium iodide bound to DNA was measured and apoptosis analysed using FACS analysis (FACSVantage SE FACS; Becton Dickinson, Oxford, UK) [29].

Isolation of islets of Langerhans and RT-PCR of Tctp Islets were isolated as previously described [30]. The study was conducted in accordance with the Principles of Laboratory Care. Total RNA was isolated using a reagent (TRI reagent, Sigma) according to the manufacturer's protocol. RT-PCR was performed using primers corresponding to nucleotides 
275-295 and 537-557 of the mouse Tctp (accession number NM_009429), respectively.

Fatty acid incubation MIN6 or HIT-T15 cells were seeded on six-well plates and grown overnight. Palmitate was coupled to fatty acid-free BSA at a 5:1 molar ratio and added to the culture medium to final concentration of $0.5 \mathrm{mmol} / \mathrm{l}$ palmitate and $0.68 \%$ (wt/vol.) BSA. Cells were incubated for $24 \mathrm{~h}$ before use. Isolated islets were cultured for $16 \mathrm{~h}$ in DMEM containing $11 \mathrm{mmol} / \mathrm{l}$ glucose, hand-picked and incubated for $24 \mathrm{~h}$ in DMEM containing 3 or $17 \mathrm{mmol} / \mathrm{l}$ glucose in the presence or absence of $0.5 \mathrm{mmol} / 1$ palmitate.

Overproduction of TCTP and TUNEL assay Cells were transfected with $0.5 \mu \mathrm{g}$ pcDNA3 containing the coding region of full-length mouse Tctp [16] or pcDNA3 empty vector using lipofectamine (Invitrogen) as described previously [27]. Cells at $24 \mathrm{~h}$ post-transfection were incubated with palmitate for 8 or $24 \mathrm{~h}$. Cells were fixed and the TUNEL assay was performed according to the manufacturer's instructions (Click-iT TUNEL Alexa Fluor 488; Invitrogen). The number of TCTP-overproducing cells and those positive for TUNEL staining were counted. Two controls were used: (1) cells transfected with pcDNA3; and (2) untransfected cells on the TCTP transfected plates in which TCTP overproduction was not visible.

Mass spectroscopy Proteins were trypsin-digested using a robotic digester (Ettan digester; GE Biosciences, UK). Peptide mass fingerprints were acquired using Matrixassisted laser desorption/ionisation time-of-flight mass spectrometer (MALDI-TOF; Waters Micromass, Waterloo, ON, Canada) with data acquisition and processing done with a software package (MassLynx; Waters, Elstree, UK). Database searching was performed by a software tool (ProteinLynx, Waters) using a peptide tolerance of $50 \mathrm{ppm}$.

\section{Results}

TCTP levels are regulated by glucose Proteomic analysis of MIN6 pancreatic beta cell homogenates identified 84 proteins (Fig. 1a, Electronic supplementary material [ESM] Tables 1-3). Of the proteins identified by MALDI-TOF, 11 were found to be differentially produced at 25 vs $3 \mathrm{mmol} / \mathrm{l}$ glucose-containing medium (Fig. 1b). The most greatly upregulated proteins were the cytoskeletal proteins tubulin and actin (2- to 4.5-fold). As one of the next in line, TCTP was upregulated by $\sim 1.8$-fold. This protein has not previously been identified as a glucose-regulated protein and thus we decided to further investigate TCTP levels in MIN6 cells.
To confirm the proteomics data, the two dimensional gels were probed with a monoclonal anti-TCTP antibody and TCTP levels compared between non-stimulatory $(3 \mathrm{mmol} / \mathrm{l})$ and stimulatory ( $25 \mathrm{mmol} / \mathrm{l})$ glucose concentrations (Fig. 2a). The same TCTP band that was identified by MALDI-TOF and image analysis software (PDQuest, Bio-Rad Laboratories, Hemel Hempstead, UK), and had a molecular mass of $\sim 23 \mathrm{kDa}$ and an isoelectric point of 4.3 was also recognised by the TCTP-specific antibody at both glucose concentrations. The intensity of this protein band increased by 1.8 - to 2.5 -fold at stimulatory glucose concentration (Fig. 2b). The TCTP antibody appeared to be very specific and cross-reacted with a protein of $\sim 21$ to $23 \mathrm{kDa}$ on one dimensional SDS-PAGE (Fig. 2c), where similar upregulation of TCTP production was observed to that on two-dimensional SDS-PAGE (Fig. 2d). Tctp mRNA was detected in primary islets of Langerhans and MIN6 cells (Fig. 2e). Moreover, TCTP protein levels were also increased in primary rat islets of Langerhans at stimulatory glucose concentration (Fig. 2d, f, g).

Post-translational modification of TCTP is regulated by glucose We repeatedly observed a slight 'smear' of the TCTP band to the acidic region or even a clearly more acidic isoform at non-stimulatory glucose concentration (Fig. 3). We therefore investigated whether the variation of the TCTP spots (Fig. 3) may be caused by differential post-translational modifications. Potential TCTP post-translational modifications had been previously predicted by our bioinformatic analysis (NetPhos 2.0, http://www.cbs.dtu.dk/services/NetPhos/, accessed 15 March 2008). Three potential phosphorylation sites for serine, two for tyrosine and one for threonine were predicted. In addition, potential glycosylation sites (for N- and O-linked glycosylation) were also predicted for TCTP.

MIN6 whole-cell lysates were separated by two dimensional SDS-PAGE, using narrow range ( $\mathrm{pH} 3-5$ ) IPG strips to increase the resolution and improve the separation of the two proteins recognised by the TCTP antibody. Using antiphosphoserine and anti-phosphotyrosine antibodies, we observed that the $23 \mathrm{kDa}$ TCTP was apparently dephosphorylated on these residues in response to glucose stimulation (Fig. 3). The presence of a phosphorylated TCTP isoform was confirmed by phosphostaining (ProQ Diamond) (Fig. 3) and subsequent identification of the protein band with quadrupole time-of-flight (Q-TOF) mass spectroscopy analysis. We also investigated the potential glycosylation of TCTP. However, the monoclonal antibody against O-GlcNAc modification or the glycoprotein stain Emerald 488 (Pro-Q) produced very high background and many non-specific staining signals. Thus, the glycosylation state of TCTP proteins could not be resolved convincingly. Nevertheless, regulation of TCTP production by glucose and dephosphorylation on serine and tyrosine residues were clearly demonstrated. 
Fig. 1 Proteomic analysis of MIN6 pancreatic beta cells. a MIN6 cell homogenates $(200 \mu \mathrm{g})$ were loaded on to $24 \mathrm{~cm}$ non-linear IPG strip (pH 3-10), subsequently separated on $12 \%$ (vol./vol.) SDSPAGE in the second dimension and stained with colloidal Coomassie blue. The image was generated using a software tool (PDQuest). The protein spots were excised from the gels, digested with trypsin and identified by MALDI-TOF mass spectroscopy. The identified spots are designated with a protein abbreviation (for details see ESM). b List of differentially produced proteins in stimulated vs non-stimulated conditions. Cells were incubated in 3 or $25 \mathrm{mmol} / \mathrm{l}$ glucosecontaining media for $24 \mathrm{~h}$ and difference in production given as ratio of $25: 3 \mathrm{mmol} / 1$. Cell homogenates were separated on 2DGE. Differential production was analysed using PDQuest. A minimum of six gels were analysed for each condition

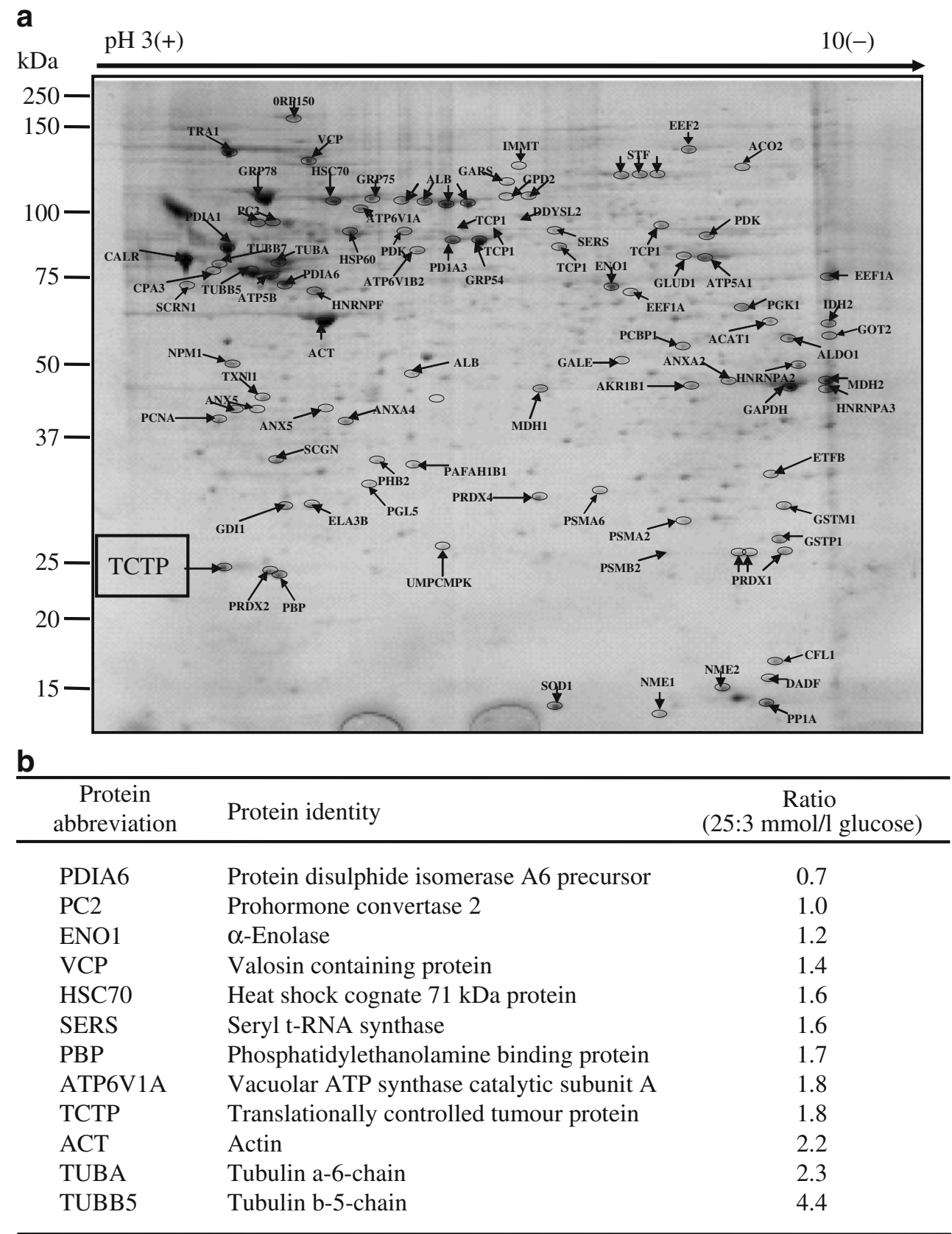

Increased nuclear localisation of TCTP in response to glucose Post-translational modifications can determine subcellular localisation and activity of proteins. Many proteins have been reported to translocate to the nucleus upon dephosphorylation [31-33]. Since TCTP is dephosphorylated at stimulatory glucose concentration, we next investigated whether the subcellular localisation of TCTP is altered by glucose. Immunocytochemistry revealed that TCTP was largely localised to the cytosol. Due to the strong cytosolic staining, it was impossible to establish whether TCTP is associated with any cellular organelles in non-stimulated cells (Fig. $4 \mathrm{a}, \mathrm{e}$ ). In contrast, in response to glucose stimulation, TCTP showed clear nuclear local- isation (Fig. 4b, d, f, g), while a significant proportion of the protein remained in the cytosol.

Reduction of TCTP protein production results in enhanced beta cell death To investigate the physiological role of TCTP in pancreatic beta cells, gene knockdown experiments were performed using siRNA. Various siRNA target sequences were tested to obtain a reduction in TCTP protein levels by at least $40 \%$. The largest decrease in TCTP level was achieved at $96 \mathrm{~h}$ post-transfection (Fig. 5a). This time point was used for further apoptosis and insulin secretion experiments. During the siRNA experiments, a significant number of dead cells were observed, which led us to investigate the potential role 


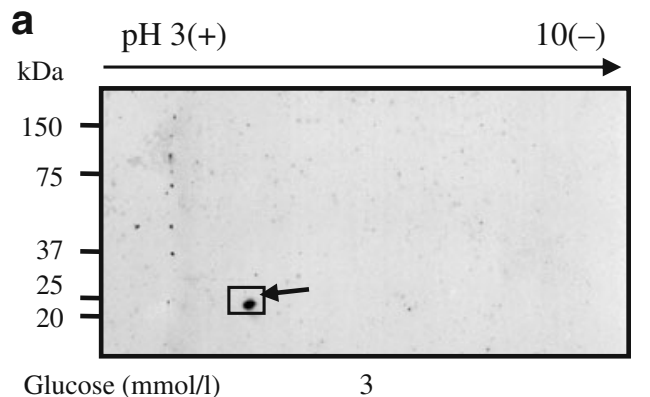

Glucose $(\mathrm{mmol} / \mathrm{l})$

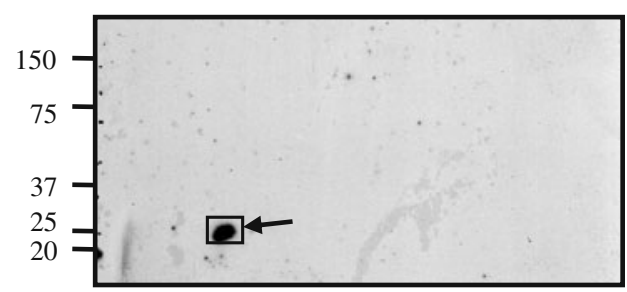

Glucose (mmol/l) b

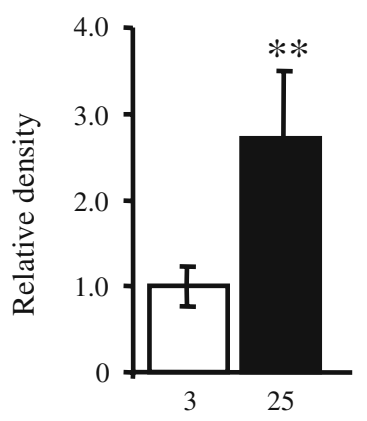

C

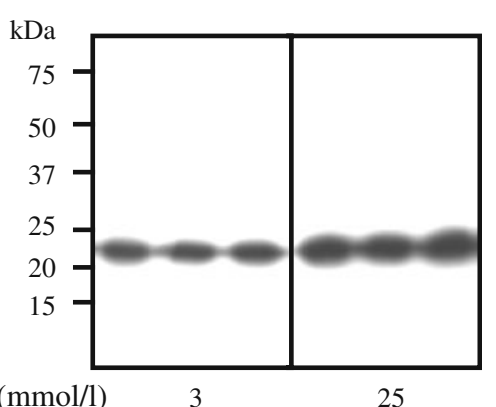

Glucose (mmol/l)

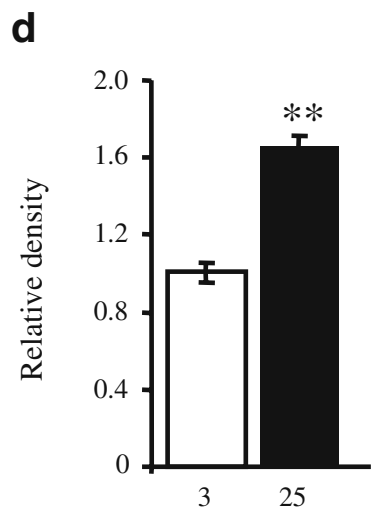

Fig. 2 TCTP protein levels are regulated by glucose. a Cells were incubated for $24 \mathrm{~h}$ in 3 or $25 \mathrm{mmol} / 1$ glucose-containing media. Cell homogenates were separated on 2DGE using 7 cm IPG strips ( $\mathrm{pH} 3-10$ ). Proteins were then transferred to nitrocellulose membranes. Membranes were probed with a TCTP-specific monoclonal antibody $(1: 1,000$ dilution). The resulting TCTP band is highlighted by rectangles. b Quantification of TCTP protein levels in $25 \mathrm{vs} 3 \mathrm{mmol} / 1$ glucosecontaining media. TCTP bands were scanned and their density measured using a software package (ImageQuant, GE Healthcare). Equal amounts of proteins were loaded on each gel and a minimum of six gels were analysed for each condition. Quantification of TCTP levels on one-dimensional SDS-PAGE. c The nitrocellulose membranes were stained for total protein with Ponceau red prior to immunostaining with an anti-TCTP antibody. d Membranes were scanned and the density of the TCTP signal in each protein lane measured and normalised to that of the total protein. A minimum of six gels were
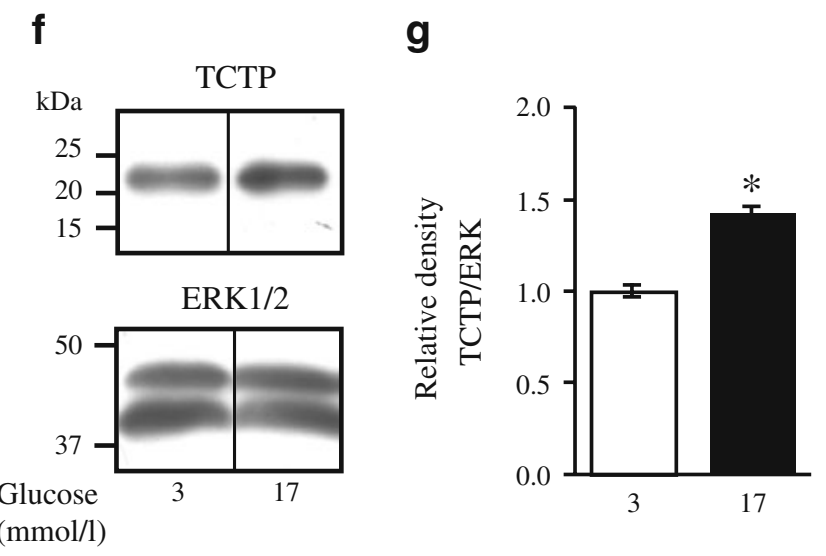

analysed for each condition. e Expression of Tctp mRNA in MIN6 cells and primary rat islets of Langerhans. PCR was performed with specific primers for $T c t p$ and $A c t b$ (encoding $\beta$-actin). f Rat islets of Langerhans were incubated for $24 \mathrm{~h}$ in medium containing either 3 or $17 \mathrm{mmol} / 1$ glucose. Homogenates were separated on SDS-PAGE and immunoblotting was performed as described above (a) (except TCTP antibody dilution 1:100). Equal amounts of proteins were loaded on each lane $(50 \mu \mathrm{g})$. The same immunoblot was probed with a rabbit polyclonal anti-ERK1/2 antibody (1:1,000 dilution) [28]. The signal density of each band was measured and (g) TCTP: ERK1/2 ratio calculated. Three independent experiments were carried out and each sample was loaded in duplicates. The films were exposed for various periods of time. For density measurements an exposure time was selected, where the chemiluminescence reaction was still in the linear phase. Error bars $(\mathbf{b}, \mathbf{d}, \mathbf{g})$ represent standard error; ${ }^{*} p<0.05$ and $* * p<0.01$ of TCTP in apoptosis. The extent of apoptosis was quantified by propidium iodide staining and flow cytometry [29]. MIN6 beta cells transfected with siRNA specific to TCTP showed significantly higher cell death than cells transfected with the scrambled RNA (Fig. 5b). These data suggest that decreased TCTP production reduces the viability of beta cells. We next investigated the effect of reduced TCTP protein levels on glucose-induced insulin secretion. Glucose elicited an approximately threefold increase in insulin secretion; however, no significant difference between the various conditions was observed (Fig. 5c).

Palmitate reduces TCTP protein production through mechanisms involving endoplasmic reticulum stress Having 


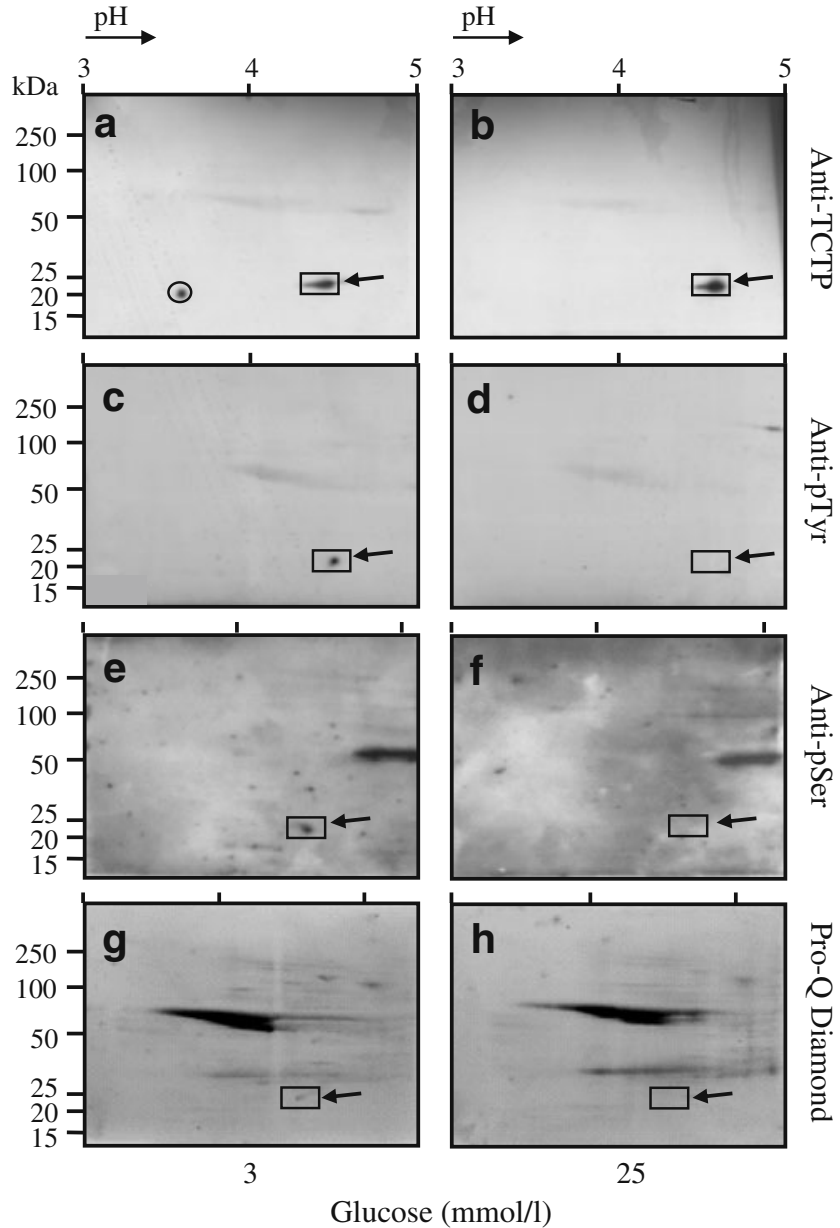

Fig. 3 TCTP phosphorylation is regulated by glucose. MIN6 cells were incubated for $24 \mathrm{~h}$ in the presence of $3(\mathbf{a}, \mathbf{c}, \mathbf{e}, \mathbf{g})$ or $25(\mathbf{b}, \mathbf{d}, \mathbf{f}$, h) $\mathrm{mmol} / 1$ glucose-containing medium as labelled and the cell homogenates were separated by 2DGE on $7 \mathrm{~cm}$ IPG strips (pH 3-5), followed by $4-12 \%$ (vol./vol.) SDS-PAGE in the second dimension. The proteins were transferred to nitrocellulose membranes and probed, as labelled, with an anti-TCTP monoclonal antibody $(1: 1,000 ; \mathbf{a}, \mathbf{b})$, an anti-phosphotyrosine antibody $(1: 500 ; \mathbf{c}$, d) or an antiphosphoserine antibody $(1: 250 ; \mathbf{e}, \mathbf{f})$. A gel was also stained for phosphoproteins using Pro-Q Diamond $(\mathbf{g}, \mathbf{h})$ and counterstained for total proteins with SYPRO Ruby. The phosphorylated protein corresponding to TCTP (rectangles) was excised and its identity confirmed by Q-TOF mass spectroscopy. Antibodies or stains used are indicated on the right. A minimum of three gels were analysed for each condition

demonstrated that in normal beta cells glucose stimulation resulted in upregulation of TCTP protein (Fig. 2), we next investigated whether TCTP levels are reduced when the cells were subjected to stress conditions. For this purpose, the cells were incubated with $0.5 \mathrm{mmol} / \mathrm{l}$ palmitate for $24 \mathrm{~h}$. TCTP protein levels were significantly reduced (by about $40 \%$ ) following fatty acid treatment (Fig. 6a). In parallel, apoptosis was measured and significant death was observed in cells incubated with palmitate compared with controls (Fig. 6b). The same effect of palmitate on TCTP protein levels was observed in primary rat islets of Langerhans
Glucose

$(\mathrm{mmol} / \mathrm{l})$
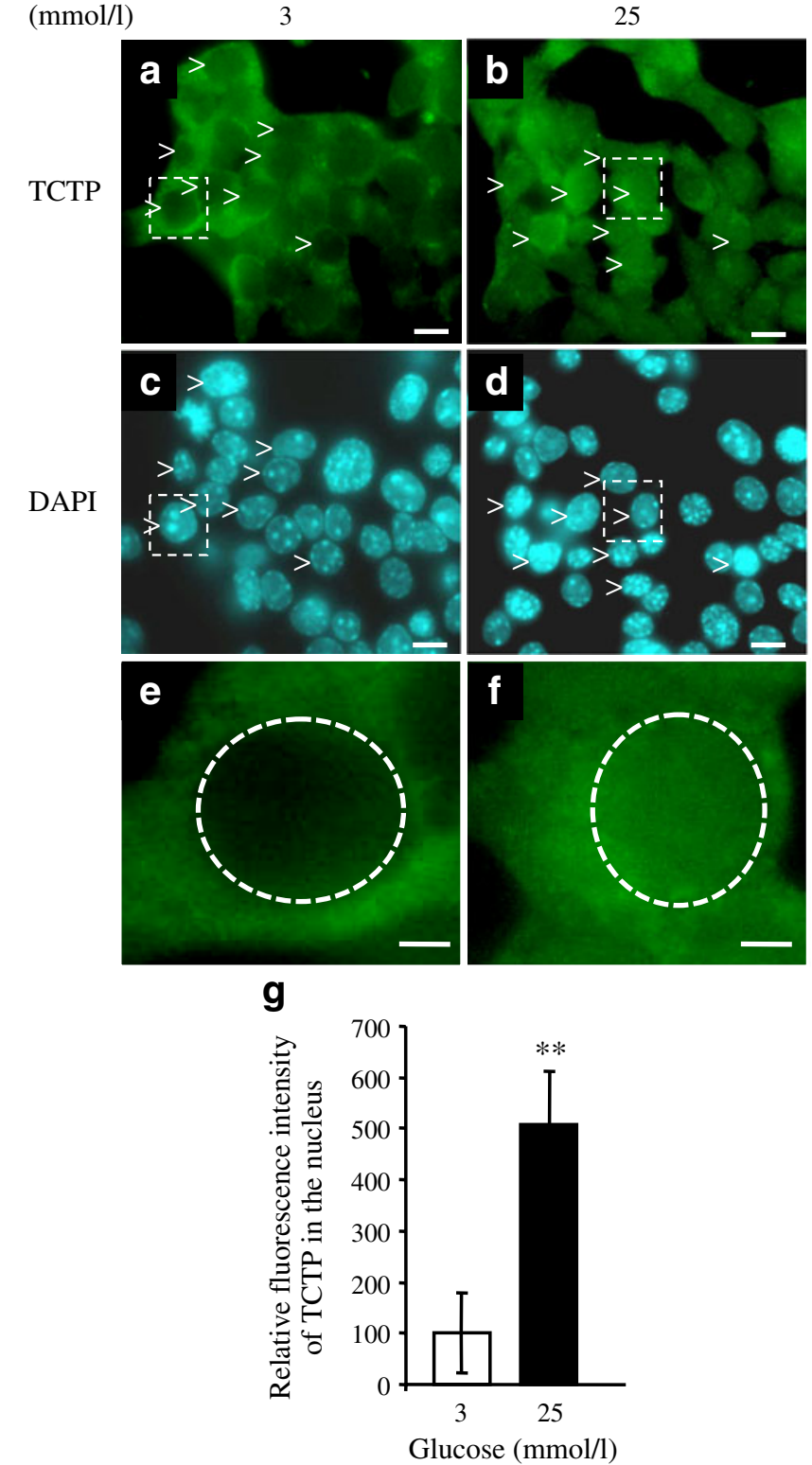

Fig. 4 Glucose stimulation induces increased nuclear localisation of TCTP. a, c, e Immunolocalisation of TCTP in MIN6 cells at low $(3 \mathrm{mmol} / \mathrm{l})$ and $(\mathbf{b}, \mathbf{d}, \mathbf{f})$ high $(25 \mathrm{mmol} / \mathrm{l})$ glucose. Cells were grown on poly-L-lysine-coated glass coverslips and incubated with glucose for $24 \mathrm{~h}$. Cells were fixed with paraformaldehyde, washed and probed with a mouse monoclonal anti-TCTP antibody (1:500) and visualised with a goat anti-mouse Alexa-488 secondary antibody (1:500 dilution) (a, b, e, f). Nuclei were identified by DAPI staining (c, d). Arrowheads show nuclei of the cells on TCTP and DAPI images. Dotted outlines $(\mathbf{a}-\mathbf{d})$ show cells seen $(\mathbf{e}, \mathbf{f})$ on an expanded scale. Scale bars $10 \mu \mathrm{m}(\mathbf{a}-\mathbf{d})$ or $2.5 \mu \mathrm{m}(\mathbf{e}, \mathbf{f})$. g Quantification of nuclear localisation. The imaging was performed using same confocal settings for all conditions and the intensity of nuclear staining was quantified with a software package (Volicity). Three regions were randomly selected on each coverslip in three independent experiments. The total cell number analysed at 3 and $25 \mathrm{mmol} / 1$ glucose was 94 and 65 , respectively. Error bars represent standard error; $* * p<0.01$ 

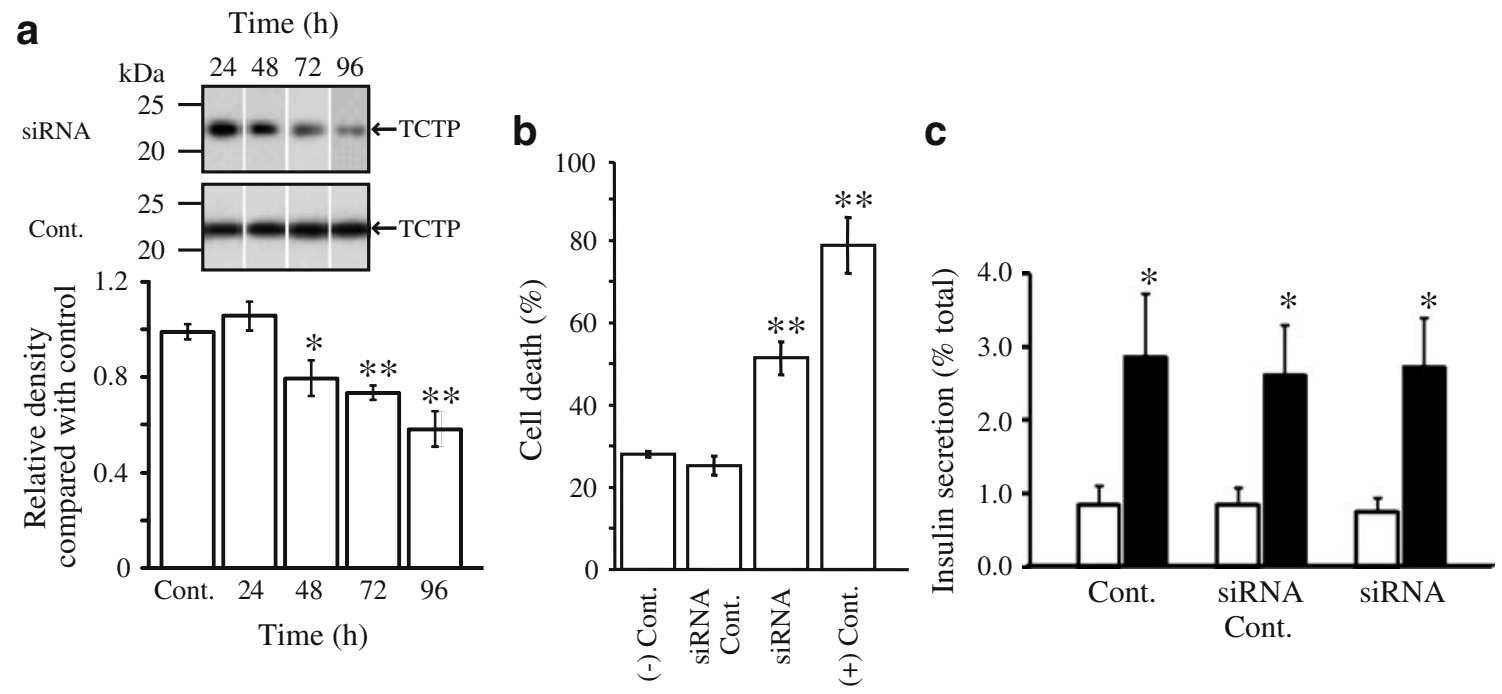

Fig. 5 Suppressed production of TCTP leads to reduced cell survival, but does not affect glucose-stimulated insulin secretion. a siRNA suppression of TCTP protein production. MIN6 cells were kept in normal growth medium containing $25 \mathrm{mmol} / \mathrm{l}$ glucose and transfected with $80 \mathrm{pmol} / 1$ commercial siRNA for TCTP. Total protein was extracted 24, 48, 72 and $96 \mathrm{~h}$ after transfection. Protein $(15 \mu \mathrm{g})$ was separated by SDS-PAGE, transferred to nitrocellulose membranes and probed with a mouse anti-TCTP antibody (1:1,000 dilution). Cont., control, i.e. scrambled RNA. Protein bands were scanned and their density measured using a software tool (ImageQuant). Relative densities comparing the transfected samples at each time point with the scrambled RNA control are shown. Four independent experiments were performed and each sample was loaded in triplicate. b Reduced levels of TCTP following siRNA treatment lead to increased cell death. Cell death was determined by FACS analysis using propidium

(Fig. 6c), where TCTP protein levels were reduced by $\sim 50 \%$ (Fig. 6d). Since palmitate induces endoplasmic reticulum (ER) stress in pancreatic beta cells [34-36], we next investigated whether thapsigargin, a chemical ER stress inducer, affected TCTP protein level. We observed a significant reduction (about $\sim 50 \%$ ) of TCTP protein production after $8 \mathrm{~h}$ thapsigargin treatment (Fig. 6e, f).

Increased TCTP protein production protects cells from apoptosis To test whether the increased TCTP protein level seen after glucose stimulation (Fig. 2) can improve cell viability and partially protect cells from palmitate-induced cell death, we overproduced TCTP. The transfection efficiency was about $20 \%$. Therefore apoptotic cells were counted in the TCTP-overproducing cells $(n=125$ and 230 cells following 8 and $24 \mathrm{~h}$ incubation with palmitate, respectively; Fig. 7a). The proportion of cells positive for TUNEL staining was significantly lower in cells visibly overproducing TCTP than in neighbouring untransfected cells on the same plate or in the control plasmid-transfected cells (Fig. 7b). A similar proportion of apoptotic cells $(\sim 40 \%)$ was obtained in palmitate-treated cells transfected with the empty control vector $(n=397$ cells; Fig. 7 b) or in iodide staining in cells transfected with siRNA or scrambled RNA at $96 \mathrm{~h}$ post transfection. (-) Cont., cells cultured for $96 \mathrm{~h}$ without any treatment; siRNA Cont., cells transfected with scrambled RNA; siRNA, cells transfected with siRNA for $T c t p ;(+)$ Cont., cells treated with methanol overnight at $-20^{\circ} \mathrm{C}$ and used as positive control for cell death. The graph represents three independent experiments with each measurement performed in triplicates. Note: cells were cultured for $144 \mathrm{~h}$ in total, hence the high basal cell death shown here. c Glucosestimulated insulin secretion in non-transfected cells and cells transfected with scrambled RNA or siRNA. Insulin secretion was quantified $96 \mathrm{~h}$ post transfection. White bars, insulin secretion at $3 \mathrm{mmol} / \mathrm{l}$ glucose; black bars, insulin secretion at $25 \mathrm{mmol} / \mathrm{l}$ glucose. The graph represents three independent experiments with each measurement performed in triplicates. Error bars represent standard error; ${ }^{*} p<0.05,{ }^{* *} p<0.01$

untransfected cells ( $n=476$ cells; Fig. $7 \mathrm{~b}$ ), as observed previously following $24 \mathrm{~h}$ incubation with palmitate (Fig. 6b). Our data thus indicate that TCTP overproduction significantly reduces palmitate-induced cell death (Fig. 7a).

To better understand the possible mechanism by which increased TCTP protein levels reduce cell death, we next tested whether a higher proportion of TCTP becomes associated with the mitochondria under this condition. In non-stimulatory glucose condition only a very small amount of TCTP was detectable in the mitochondrial fraction, whereas at stimulatory glucose levels the amount of TCTP found in this subcellular fraction was clearly increased (Fig. 7c). This supports a model, according to which TCTP anchors to the mitochondrial membrane and antagonises the action of the pro-apoptotic protein BAX, which is involved in regulating the membrane permeability [10].

\section{Discussion}

To contribute to the understanding of glucose regulation in pancreatic beta cells, we investigated the differential regulation of proteins in response to high vs low glucose 
Fig. 6 Palmitate treatment and ER stress lead to reduced TCTP protein levels. a Palmitate reduces TCTP protein level. Cells were incubated with $0.68 \%$ (wt $/ \mathrm{vol}$.) BSA with or without $0.5 \mathrm{mmol} / 1$ palmitate for $24 \mathrm{~h}$. Equal amounts of protein $(15 \mu \mathrm{g})$ were loaded on each lane. Relative TCTP protein levels were assessed by immunoblotting using a mouse monoclonal anti-TCTP antibody (1:1,000 dilution). The same immunoblot was probed with a mouse monoclonal antiGAPDH antibody. The signal density of each band was measured and TCTP/GAPDH ratio calculated, which in palmitate-incubated cells was compared with cells cultured with BSA only. Five independent experiments were carried out and each sample was loaded in triplicate. b Apoptosis in cells incubated in the absence or presence of palmitate was determined as described (Fig. 5b). Note: cells were cultured for $48 \mathrm{~h}$ in total for experiments shown here (b), hence the decreased basal cell death compared with Fig. 5b. The graph represents three independent experiments with each measurement performed in triplicates. c Palmitate reduces TCTP protein level in primary rat islets of Langerhans. TCTP was detected in rat islets of Langerhans after $24 \mathrm{~h}$ incubation in the presence and absence of $0.5 \mathrm{mmol} / \mathrm{l}$ palmitate. Equal amounts of protein $(50 \mu \mathrm{g})$ were loaded on each lane and the mouse anti-TCTP antibody was used in 1:100 dilution. TCTP intensity was normalised to ERK1/2, as the anti-ERK1/2 antibody worked better in these samples than the antibody against GAPDH. Quantification (d) was carried out as described (Fig. 2d). e MIN6 cells were incubated for $8 \mathrm{~h}$ in the presence and absence of the pharmacological ER stressor thapsigargin $(0.4 \mu \mathrm{mol} / \mathrm{l})$. Blots and quantification (f) were performed as described above $(\mathbf{a}, \mathbf{c}, \mathbf{d})$. Error bars represent standard error; ${ }^{*} p<0.05,{ }^{*} p<0.01$

concentrations. Using a proteomics approach, we identified 11 out of 84 proteins that are differentially regulated (Fig. 1, ESM Tables 1-3). Of these proteins, we initially selected TCTP for a more detailed investigation.

Our study demonstrates that TCTP protein levels and subcellular distribution are regulated by glucose in pancreatic beta cells. Since increased fatty acid circulation is a major factor in the development of type 2 diabetes and fatty acids have been shown to be toxic to beta cells [34-37], we also investigated the effect of a fatty acid on TCTP protein levels in beta cells. Palmitate downregulated TCTP protein levels and resulted in increased cell death (Fig. 6a-d). Thus, the cytotoxic effect of palmitate is, at least in part, due to reduced production of this anti-apoptotic protein. In contrast, overproduction of TCTP protein protected beta cells from apoptosis (Fig. 7a, b). Our results thus imply that TCTP levels influence the sensitivity of the beta cell to apoptosis. TCTP levels have been shown to be highly regulated in response to a wide range of extracellular signals, as reviewed by others $[6,21,22]$. However, to our knowledge, this is the first demonstration of regulation of TCTP levels in response to alterations in glucose or fatty acid concentrations.

Protein synthesis in beta cells is highly regulated in response to alterations of glucose concentrations. In particular, mechanisms of the unfolded protein response (UPR), a physiological ER-stress response, are involved in this regulation. This includes activation of the PKR-like ER kinase (PERK) and subsequent phosphorylation of initiation factor a

b
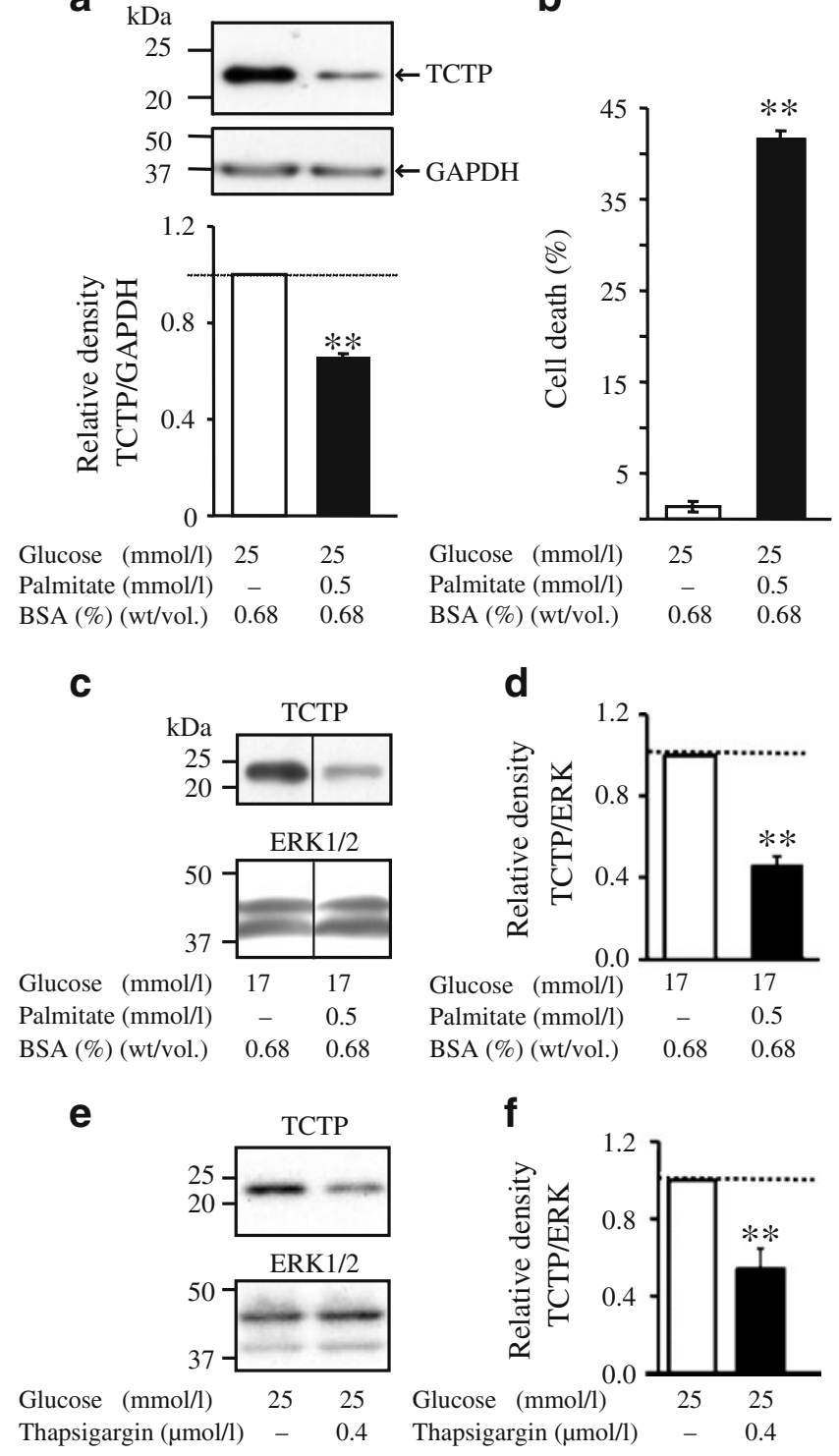

Glucose $(\mathrm{mmol} / \mathrm{l}) \quad 25 \quad 25$ Palmitate $(\mathrm{mmol} / \mathrm{l}) \quad-\quad 0.5$ BSA $(\%)(w t / v o l) \quad 0.68 \quad$. GAPDH

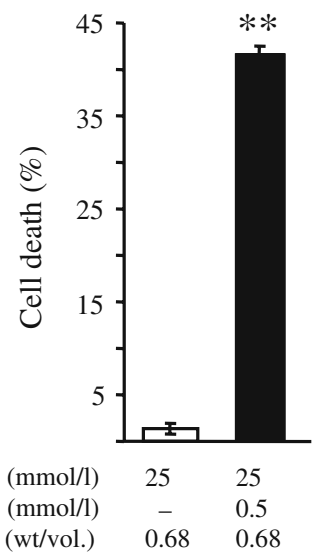

f

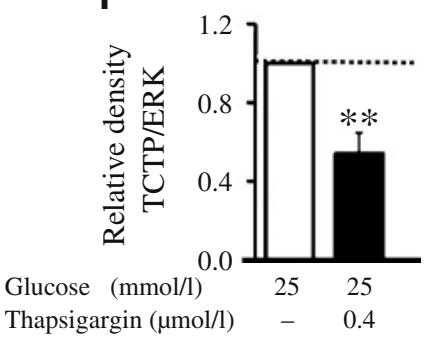

eIF $2 \alpha$, leading to (local) inhibition of protein synthesis. At low glucose concentrations, PERK is activated, resulting in increased eIF $2 \alpha$ phosphorylation and inhibition of ER protein (and therefore proinsulin) synthesis [38, 39]. We have previously demonstrated that TCTP synthesis is downregulated through phosphorylation of eIF $2 \alpha$ by PKR in cellular stress conditions [11, 24]. Although we did not specifically address the role of PERK in these studies, both kinases are probably involved in TCTP regulation, as both are activated upon ER-stress [40]. We conclude that the glucosedependent regulation of TCTP synthesis in beta cells observed in this study (Fig. 2) is also likely to be mediated through a mechanism involving eIF $2 \alpha$ phosphorylation.

While mechanisms of the UPR are involved in physiological regulation of beta cells through glucose, they may also be activated under chronic stress conditions, such as 
Fig. 7 Increased levels of TCTP leads to its translocation to the mitochondria and enhanced protection from cell death. a Overproduction of TCTP protects MIN6 cells from palmitate-induced cell death. Cells were transfected with a plasmid encoding the full-length mouse Tctp or with the empty control vector and incubated at $24 \mathrm{~h}$ post transfection with $0.5 \mathrm{mmol} / 1$ palmitate for $8 \mathrm{~h}(n=14)$ and $24 \mathrm{~h}$ $(n=18)$. The experiment was carried out as described in the Methods. Examples of TCTP overproducing cells are indicated with arrows. Cell nuclei positive for TUNEL staining are labelled by arrowheads and were also visualised with DAPI staining. Scale bar, $10 \mu \mathrm{m}$. b The numbers of apoptotic cells in TCTP-transfected cells (white bars), in the neighbouring un-transfected cells on the same plate (grey bars) and in cells transfected with the empty control vector pcDNA3 (black bars) were counted and plotted. Three independent experiments were performed and the number of cells counted in each condition is indicated below graph. Regions on the plates were randomly selected and all cells were analysed in a field of view. Error bars represent standard error, which was very small for the pcDNA3 $24 \mathrm{~h}$ control $(0.042) ; * *<0.01$. c TCTP partially translocates to the mitochondria in response to glucose stimulation. MIN6 cells were incubated for $24 \mathrm{~h}$ in medium containing $3 \mathrm{mmol} / 1$ or $25 \mathrm{mmol} / \mathrm{l}$ glucose. The mitochondrial pellet (Mito.P) and post-mitochondrial supernatant fraction (PMS) were obtained from centrifugation of the post-nuclear supernatant fraction (PNS) at $10,000 \times g$ for $20 \mathrm{~min}$. The Mito.P fraction was washed several times before loading on to gels. The blots were probed with the anti-TCTP antibody. PNS and PMS $(15 \mu \mathrm{g})$, and $100 \mu \mathrm{g}$ mitochondrial pellets were loaded. The same blots were probed for ERK1/2 and for the mitochondrial marker cytochrome $c$ (cyt $c$ ) for equal loading. Note the increased TCTP protein level at stimulatory glucose concentration in the PNS samples. The result is representative of four independent experiments

elevated levels of NEFA, which contribute to beta cell dysfunction in type 2 diabetes. NEFA, such as palmitate, trigger ER stress [34-37] and eventually apoptosis in cultured beta cells in vitro, as reviewed by others [41, 42]. They also induce apoptosis in primary rodent and human islets of Langerhans [34]. In beta cells, palmitate has been demonstrated to activate PERK and phosphorylation of eIF $2 \alpha$, resulting in inhibition of translation initiation [35, $36,43]$. In a recent study, we demonstrated downregulation of TCTP levels in mouse embryo fibroblasts under some, but not all ER stress conditions [11]. TCTP was particularly downregulated in $\mathrm{Ca}^{2+}$ stress conditions (including thapsigargin treatment) in a manner dependent on active PKR and eIF $2 \alpha$ phosphorylation. This is consistent with our observation that TCTP is downregulated in beta cells under stress induced by palmitate or thapsigargin (Fig. 6). Downregulation of anti-apoptotic proteins is an important prerequisite for apoptosis to occur, so it is not surprising that TCTP [11] and MCL-1 [44] have been found to be downregulated in $\mathrm{Ca}^{2+} / \mathrm{ER}$ stress conditions in a PKRdependent manner. Since palmitate has earlier been shown to result in activation of PERK in beta cells [35, 36, 43], we conclude that downregulation of TCTP by palmitate (Fig. 6) is mediated through PERK activation.

Our studies have also shown that overproduction of TCTP can delay apoptosis induced by thapsigargin, a
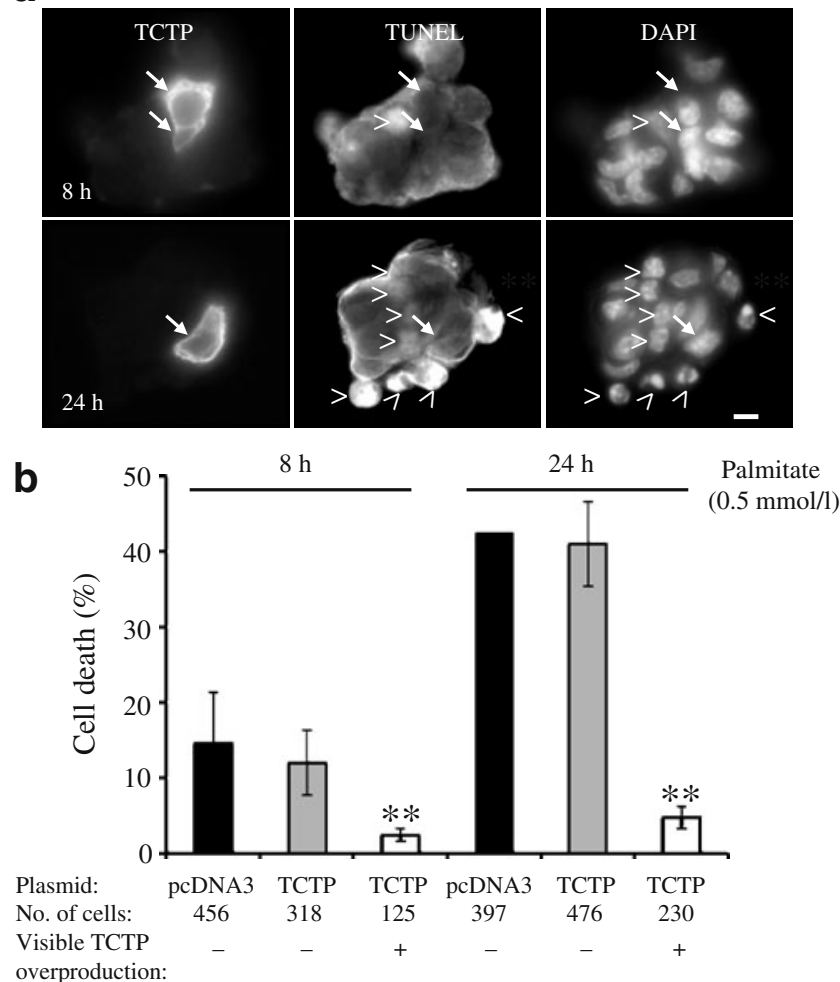

overproduction:

C
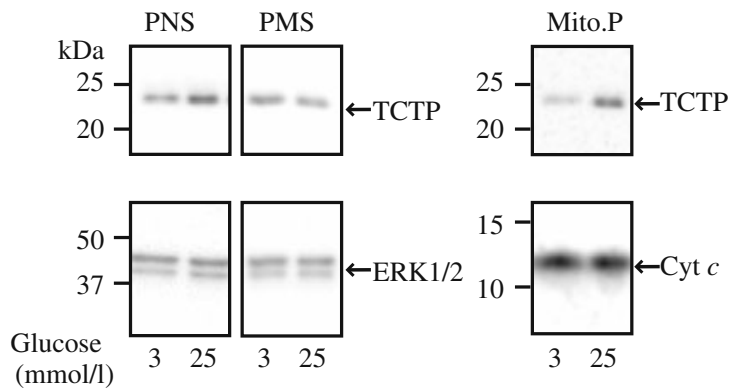

tunicamycin and etoposide [11] or palmitate (Fig. 7a). Conversely, downregulation of TCTP protein production has been reported to lead to apoptosis [10, 13, 14], consistent with the observations obtained here in Tctp knockdown experiments on beta cells (Fig. 5b). Palmitate is known to be cytotoxic to beta cells in obesity-associated animal models of diabetes, as well as in normal beta cells [34-37]. We propose that these cytotoxic effects are at least in part mediated by the inhibition of production of antiapoptotic proteins such as TCTP.

TCTP has been described as a cytosolic protein [6], but nuclear localisation has also been reported [12, 45]. Under low glucose concentrations, we observed largely cytosolic TCTP staining in beta cells, with very little staining in the nucleus. However, under high-glucose conditions we noticed a significant TCTP immunostaining in the nucleus, in addition to the cytosolic staining (Fig. 4a). Similarly to our 
finding, other recent studies have shown that TCTP can be transported to the nucleus under certain conditions [45]. Rid et al. [45] reported that under oxidative stress conditions TCTP translocates to the nucleus. There are also indications that TCTP might be involved in transcriptional regulation of specific genes in T lymphocytes [46] and in early development [47, 48]. Our current study indicates that TCTP becomes dephosphorylated on serine and tyrosine residues in response to glucose stimulation, which might be important for this nuclear translocation, as reported in other cases [31-33].

Since TCTP is an anti-apoptotic protein, we also attempted to investigate its potential co-localisation with mitochondria in beta cells. However, because TCTP is still abundantly present in the cytosol, giving rise to intense cytosolic staining, and because these cells were only poorly spread, it was not possible to localise TCTP to any specific organelles using immunocytochemistry. Instead, we used subcellular fractionation, the results of which indicated that a proportion of TCTP becomes associated with the mitochondria-enriched fraction at high vs low glucose condition (Fig. 7c). It has been demonstrated that TCTP interacts with the anti-apoptotic proteins MCL-1 and BCL-XL in vitro [8, 9]. Immunofluorescence data have also suggested that TCTP co-localises with BCL-XL [9] and MCL-1 [8] in vivo, and is therefore likely to act, like other key regulators of apoptosis, at the mitochondria. However, the interpretation of co-localisation studies $[8,9]$ is rather complicated because, as mentioned above, TCTP is highly abundant in the cytosol. A more recent study has demonstrated that the anti-apoptotic function of TCTP takes place, at least in part, at mitochondria, with TCTP inhibiting the function of BAX [10]. Our investigations (Fig. 7c) suggest that, in beta cells, TCTP partially translocates to the mitochondria in response to glucose, where it is likely to act in a similar fashion.

In summary, we have provided evidence that, in pancreatic beta cells, TCTP is positively regulated by glucose and negatively by pro-apoptotic stimuli, such as palmitate. It is involved in the protection of beta cells against apoptosis. Further studies are required to determine the precise mechanisms of the glucose-dependent regulation of TCTP and its translocation to the nucleus, as well as the significance of this translocation for its anti-apoptotic function. Further studies are also required to elucidate regulation of TCTP by other proapoptotic stimuli in beta cells, as well as the importance of TCTP in animal models of type 2 diabetes.

Acknowledgements We thank J. Slinn and M. Lewis (Centre for Research in Biomedicine, Faculty of Health and Life Sciences, University of the West of England, Bristol, UK) for their technical assistance and advice on mass spectroscopy analysis. This study was supported by grants from the Wellcome Trust, the Biotechnology and Biological Sciences Research Council and the Medical Research Council to A. Varadi. S. Lajus was supported by a Marie Curie Intra European Fellowship within the 7th European Community Framework Programme.
Duality of interest The authors declare that there is no duality of interest associated with this manuscript.

\section{References}

1. Schedel J, Distler O, Woenckhaus M et al (2004) Discrepancy between mRNA and protein expression of tumour suppressor maspin in synovial tissue may contribute to synovial hyperplasia in rheumatoid arthritis. Ann Rheum Dis 63:1205-1211

2. Wang G, Lai FM, Lai KB et al (2009) Discrepancy between intrarenal messenger RNA and protein expression of ACE and ACE2 in human diabetic nephropathy. Am J Nephrol 29:524-531

3. Wang D (2008) Discrepancy between mRNA and protein abundance. Comput Biol Chem 32:462-468

4. Chitpatima ST, Makrides S, Bandyopadhyay R et al (1988) Nucleotide sequence of a major messenger RNA for a 21 kilodalton polypeptide that is under translational control in mouse tumor cells. Nucleic Acids Res 16:2350-2364

5. Bommer UA, Lazaris-Karatzas A, De Benedetti A et al (1994) Translational regulation of the mammalian growth-related protein P23: involvement of eIF-4E. Cell Mol Biol Res 40:633-641

6. Bommer UA, Thiele BJ (2004) The translationally controlled tumour protein (TCTP). Int J Biochem Cell Biol 36:379-385

7. Zhang D, Li F, Weidner D et al (2002) Physical and functional interaction between myeloid cell leukemia 1 protein (MCL1) and fortilin. The potential role of MCL1 as a fortilin chaperone. J Biol Chem 277:37430-37438

8. Liu H, Peng HW, Cheng YS et al (2005) Stabilization and enhancement of the antiapoptotic activity of mcl-1 by TCTP. Mol Cell Biol 25:3117-3126

9. Yang Y, Yang F, Xiong Z et al (2005) An N-terminal region of translationally controlled tumor protein is required for its antiapoptotic activity. Oncogene 24:4778-4788

10. Susini L, Besse S, Duflaut D et al (2008) TCTP protects from apoptotic cell death by antagonizing bax function. Cell Death Differ 15:1211-1220

11. Bommer UA, Heng C, Perrin A et al (2010) Roles of the translationally controlled tumour protein (TCTP) and the doublestranded RNA-dependent protein kinase, PKR, in cellular stress responses. Oncogene 29:763-773

12. Li F, Zhang D, Fujise K (2001) Characterization of fortilin, a novel antiapoptotic protein. J Biol Chem 276:47542-47549

13. Chen SH, Wu PS, Chou CH et al (2007) A knockout mouse approach reveals that TCTP functions as an essential factor for cell proliferation and survival in a tissue- or cell type-specific manner. Mol Biol Cell 18:2525-2532

14. Hsu YC, Chern JJ, Cai Y et al (2007) Drosophila TCTP is essential for growth and proliferation through regulation of dRheb GTPase. Nature 445:785-788

15. Cans C, Passer BJ, Shalak V et al (2003) Translationally controlled tumor protein acts as a guanine nucleotide dissociation inhibitor on the translation elongation factor eEF1A. Proc Natl Acad Sci USA 100:13892-13897

16. Gachet Y, Tournier S, Lee M et al (1999) The growth-related, translationally controlled protein P23 has properties of a tubulin binding protein and associates transiently with microtubules during the cell cycle. J Cell Sci 112:1257-1271

17. Xu A, Bellamy AR, Taylor JA (1999) Expression of translationally controlled tumour protein is regulated by calcium at both the transcriptional and post-transcriptional level. Biochem J 342:683689

18. Yarm FR (2002) Plk phosphorylation regulates the microtubulestabilizing protein TCTP. Mol Cell Biol 22:6209-6221 
19. MacDonald SM, Rafnar T, Langdon J et al (1995) Molecular identification of an IgE-dependent histamine-releasing factor. Science 269:688-690

20. Kang HS, Lee MJ, Song H et al (2001) Molecular identification of IgE-dependent histamine-releasing factor as a B cell growth factor. J Immunol 166:6545-6554

21. Schmidt I, Fähling M, Nafz B, Skalweit A, Thiele BJ (2007) Induction of translationally controlled tumor protein (TCTP) by transcriptional and post-transcriptional mechanisms. FEBS J 274:5416-5424

22. Yubero N, Esteso G, Cardona H, Morera L, Garrido JJ, Barbancho M (2009) Molecular cloning, expression analysis and chromosome localization of the Tpt1 gene coding for the pig translationally controlled tumor protein (TCTP). Mol Biol Rep 36:1957-1965

23. Andree H, Thiele H, Fähling M, Schmidt I, Thiele BJ (2006) Expression of the human TPT1 gene coding for translationally controlled tumor protein (TCTP) is regulated by CREB transcription factors. Gene 380:95-103

24. Bommer UA, Borovjagin AV, Greagg MA et al (2002) The mRNA of the translationally controlled tumor protein P23/TCTP is a highly structured RNA, which activates the dsRNA-dependent protein kinase PKR. RNA 8:478-496

25. Tuynder M, Susini L, Prieur S et al (2002) Biological models and genes of tumor reversion: cellular reprogramming through tpt1/ TCTP and SIAH-1. Proc Natl Acad Sci USA 99:14976-14981

26. Kim SH, Cairns N, Fountoulakisc M, Lubec G (2001) Decreased brain histamine-releasing factor protein in patients with Down syndrome and Alzheimer's disease. Neurosci Lett 300:41-44

27. Varadi A, Tsuboi T, Rutter GA (2005) Myosin Va transports dense core secretory vesicles in pancreatic MIN6 beta cells. Mol Biol Cell 16:2670-2680

28. Riboulet-Chavey A, Diraison F, Siew LK et al (2008) Inhibition of AMP-activated protein kinase protects pancreatic beta cells from cytokine-mediated apoptosis and $\mathrm{CD}^{+} \mathrm{T}$ cell-induced cytotoxicity. Diabetes 57:415-423

29. Riccardi C, Nicoletti I (2006) Analysis of apoptosis by propidium iodide staining and flow cytometry. Nat Protoc 1:1458-1461

30. Diraison F, Parton L, Ferre P et al (2004) Over-expression of sterol-regulatory-element-binding protein-1c (SREBP1c) in rat pancreatic islets induces lipogenesis and decreases glucosestimulated insulin release: modulation by 5-aminoimidazole-4carboxamide ribonucleoside (AICAR). Biochem J 378:769-778

31. Nebl G, Meuer SC, Samstag Y (1996) Dephosphorylation of serine 3 regulates nuclear translocation of cofilin. J Biol Chem 271:26276-26280

32. Kaffman A, O'Shea EK (1999) Regulation of nuclear localization: a key to a door. Annu Rev Cell Dev Biol 15:291-339

33. Mutoh S, Osabe M, Inoue K (2009) Dephosphorylation of threonine 38 is required for nuclear translocation and activation of human xenobiotic receptor CAR (NR1I3). J Biol Chem 284:34785-34792

34. Cunha DA, Hekerman P, Ladriere L et al (2008) Initiation and execution of lipotoxic ER stress in pancreatic beta cells. J Cell Sci $121: 2308-2318$
35. Karaskov E, Scott C, Zhang L, Teodoro T, Ravazzola M, Volchuk A (2006) Chronic palmitate but not oleate exposure induces endoplasmic reticulum stress, which may contribute to INS-1 pancreatic beta-cell apoptosis. Endocrinology 147:3398-3407

36. Laybutt DR, Preston AM, Akerfeldt MC et al (2007) Endoplasmic reticulum stress contributes to beta cell apoptosis in type 2 diabetes. Diabetologia 50:752-763

37. Kharroubi I, Ladrière L, Cardozo AK et al (2004) Free fatty acids and cytokines induce pancreatic beta cell apoptosis by different mechanisms: role of nuclear factor-kappaB and endoplasmic reticulum stress. Endocrinology 145:5087-5096

38. Gomez E, Powell ML, Bevington A et al (2008) A decrease in cellular energy status stimulates PERK-dependent eIF2alpha phosphorylation and regulates protein synthesis in pancreatic beta cells. Biochem J 410:485-493

39. Gomez E, Powell ML, Greenman IC et al (2004) Glucosestimulated protein synthesis in pancreatic beta cells parallels an increase in the availability of the translational ternary complex (eIF2-GTP.Met-tRNAi) and the dephosphorylation of eIF2 alpha. J Biol Chem 279:53937-53946

40. Lee ES, Yoon CH, Kim YS, Bae YS (2007) The double-strand RNA-dependent protein kinase PKR plays a significant role in a sustained ER stress-induced apoptosis. FEBS Lett 581:4325-4332

41. Cnop M, Igoillo-Esteve M, Cunha DA et al (2008) An update on lipotoxic endoplasmic reticulum stress in pancreatic beta cells. Biochem Soc Trans 36:909-915

42. Eizirik DL, Cardozo AK, Cnop M (2008) The role for endoplasmic reticulum stress in diabetes mellitus. Endocr Rev 29:42-61

43. Herbert TP (2007) PERK in the life and death of the pancreatic beta cell. Biochem Soc Trans 35:1205-1207

44. Fritsch RM, Schneider G, Saur D et al (2007) Translational repression of MCL-1 couples stress-induced eIF2 $\alpha$ phosphorylation to mitochondrial apoptosis initiation. J Biol Chem 282:22551-22562

45. Rid R, Onder K, Trost A et al (2009) H(2)O(2)-dependent translocation of TCTP into the nucleus enables its interaction with VDR in human keratinocytes: TCTP as a further module in calcitriol signalling. J Steroid Biochem Mol Biol 118:29-40

46. Langdon JM, Schroeder JT, Vonakis BM, Bieneman AP, Chichester K, Macdonald SM (2008) Histamine-releasing factor/ translationally controlled tumor protein (HRF/TCTP)-induced histamine release is enhanced with SHIP-1 knockdown in cultured human mast cell and basophil models. J Leukoc Biol 84:11511158

47. Koziol MJ, Garrett N, Gurdon JB (2007) Tpt1 activates transcription of oct4 and nanog in transplanted somatic nuclei. Curr Biol 17:801-807

48. Tani T, Shimada H, Kato $\mathrm{Y}$ et al (2007) Bovine oocytes with the potential to reprogram somatic cell nuclei have a unique $23-\mathrm{kDa}$ protein, phosphorylated transcriptionally controlled tumor protein (TCTP). Cloning Stem Cells 9:267-280 